\title{
Efeito da suplementação de suínos em terminação com diferentes associações entre minerais sobre o desempenho, as características de carcaça e a viabilidade econômica
}

\author{
Cesar A. P. Garbossa
[Effect of supplementation of finishing swines with different associations between minerals on $n_{\text {Marcos A. Lopes }}$ Ma00-0003-3244-7184 \\ performance, carcass characteristics and economic viability] $\quad$ Marcos A. Lopes \\ http://orcid.org/0000-0003-1543-5763 \\ T.M.N.C Albuquerque ${ }^{1}$, V.S. Cantarelli ${ }^{2}$, C.A.P. Garbossa ${ }^{2}$, M.A. Lopes ${ }^{2}$, H. Silveirahthttps://orcid.org/0000-0002-2194-7338 \\ L.K.V. Saraiva ${ }^{3}$, A.S. Orsi ${ }^{3}$, A.A. Silva ${ }^{3}$, P.B. Faria ${ }^{2}$ Lorena K. V. Saraiva \\ ${ }^{1}$ Aluna de pós-graduação - Universidade Federal de Lavras - Lavras, MG \\ ${ }^{2}$ Universidade Federal de Lavras - Lavras, MG \\ ${ }^{3}$ Aluno de graduação - Universidade Federal de Lavras - Lavras, MG \\ http://orcid.org/0000-0003-4689-0785 \\ Arthur S. Orsi \\ https://orcid.org/0000-0001-5578-5851 \\ Angela A. e Silva \\ https://orcid.org/0000-0002-6268-8483 \\ Peter B. Faria \\ http://orcid.org/0000-0002-2890-5472
}

\section{RESUMO}

Objetivou-se, com este estudo, verificar a influência da suplementação com diferentes associações entre minerais orgânicos sobre o desempenho e as características de carcaça, bem como avaliar sua viabilidade econômica, para suínos em terminação. Foram utilizados 88 machos castrados, divididos entre quatro tratamentos: controle com dieta basal e suplementação com $\mathrm{CrFe}, \mathrm{MgSe}$ e $\mathrm{CrFeMgSe}$, durante os 28 dias que antecederam o abate. O delineamento experimental foi em blocos ao acaso, com parcela experimental representada por dois animais. Os animais suplementados com $\mathrm{CrFeMgSe}$ apresentaram piores índices de peso final, ganho de peso diário e consumo durante todo o período, com consequente redução no peso de carcaça, menor profundidade de lombo, área de olho-de-lombo e menor quantidade de carne magra na carcaça. Houve um aumento no custo da dieta para os grupos $\mathrm{CrFe}, \mathrm{MgSe}$ e CrFeMgSe, respectivamente. O uso de cromo mais ferro e magnésio mais selênio, associados dois a dois, não altera os parâmetros de desempenho e as características de carcaça. A associação dos quatro minerais, no entanto, promove piora nessas características e aumenta o custo da dieta.

Palavras-chave: custo da dieta, nutrição, suinocultura

\begin{abstract}
This study aimed to verify the influence of supplementation with different associations between organic minerals on performance, carcass characteristics and economic viability for finishing swine. 88 castrated males were divided in four treatments: control with basal diet and supplementation with $\mathrm{CrFe}, \mathrm{MgSe}$ and $\mathrm{CrFeMgSe}$ during the 28 days prior to slaughter. The experimental design was randomized blocks with an experimental plot represented by two animals. The animals supplemented with CrFeMgSe had worse final weight, daily weight gain and consumption throughout the period, with consequent reduction in carcass weight, lower loin depth, loin eye area and amount of lean meat. There was an increase in the effective operational cost of diet with $\mathrm{CrFe}$, MgSe and CrFeMgSe groups, respectively. The use of chromium plus iron and magnesium plus selenium, associated two by two, did not alter the performance parameters and carcass. However, the four minerals association promote a worsening in these characteristics and increase the cost of production.
\end{abstract}

Keywords: nutrition, pig farming, production cost

\section{INTRODUÇÃOO}

A cadeia suinícola busca sempre maior produtividade e melhor qualidade da carne e, para isso, precisa de alternativas que possibilitem a produção de carcaças que apresentem maior

Recebido em 21 de fevereiro de 2018

Aceito em 4 de dezembro de 2018

E-mail: tati.mn@hotmail.com rendimento de carne, sem, contudo, afetar o desempenho dos animais (Peres et al., 2014). Qualquer que seja a estratégia utilizada para tal fim, essa deve proporcionar maior rentabilidade no empreendimento, sem onerar demasiadamente o custo de produção. A fase de terminação é o período em que se busca maior ganho de peso, 
sem aumento na quantidade de gordura na carcaça, e, para se alcançar esse objetivo, a dieta dos animais nesse período deve fornecer nutrientes que favoreçam a síntese proteica em detrimento do acúmulo adiposo. Nesse sentido, alguns minerais agem como repartidores de nutrientes, como o cromo, o magnésio e o selênio, que têm demonstrado atuar positivamente no desempenho de suínos, melhorando o ganho de peso, a conversão alimentar dos animais, a quantidade de carne magra, além de reduzirem a espessura de gordura da carcaça (Jang et al., 2010; Tarsitano et al., 2013; Peres et al., 2014). O magnésio ainda tem sido relacionado à diminuição da liberação de hormônios, como a noradrenalina e o cortisol, favorecendo a redução do estresse do plantel (D'Souza et al., 1998); com isso o maior bemestar dos animais afetaria de forma positiva sua eficiência. O selênio tem papel importante no sistema imune pela neutralização dos radicais livres, protegendo leucócitos e macrófagos dos produtos tóxicos liberados durante a fagocitose (McDowell, 2003). Esse mecanismo está diretamente relacionado à produtividade do animal, uma vez que a geração desses radicais e a peroxidação lipídica são responsáveis pelo desenvolvimento de várias doenças que impactam diretamente a produção animal (Surai, 2000). Em relação ao ferro, são poucos os trabalhos que avaliaram seu efeito no desempenho e nas características de carcaça de suínos em terminação. Contudo, a suplementação com esse mineral pode proporcionar maiores níveis de ferro heme, um componente da mioglobina (Yu et al., 2000), aumentando, desse modo, o carreamento de oxigênio para os músculos, e, por ser um elemento essencial, com funções primordiais para grande parte dos processos fisiológicos do organismo (McDowell, 2003), pode auxiliar no metabolismo das células musculares. Assim, esses minerais, usados conjuntamente, poderiam ter um efeito benéfico no desempenho dos animais, com consequente melhora nas características de carcaça.

De modo geral, na literatura encontram-se estudos dos efeitos da suplementação com esses minerais fornecidos de forma isolada, não sendo encontradas informações referentes ao uso conjunto para suínos e muitos dos trabalhos encontrados, avaliaram fontes inorgânicas. Além disso, pouco se sabe sobre a viabilidade econômica da utilização desses minerais associados.

No presente estudo, optou-se pelo uso de minerais orgânicos pelo fato de esses apresentarem maior biodisponibilidade devido à utilização de vias de captação de aminoácidos ou peptídeos, ao invés das vias normais de captação de íons no intestino delgado, evitando-se, dessa forma, a competição entre minerais pelo mesmo transportador, o que agiliza seu transporte. Ainda, por apresentarem maior estabilidade e proteção contra as reações adversas com outros nutrientes da dieta, sua taxa de absorção é maior (Close, 1999).

Assim, objetivou-se, com este estudo, verificar a influência da suplementação com diferentes associações de minerais orgânicos sobre o desempenho e as características de carcaça, bem como analisar sua viabilidade econômica para suínos em terminação.

\section{MATERIAL E MÉTODOS}

Todos os procedimentos realizados neste estudo foram aprovados pelo Comitê de Ética de Uso de Animais da Universidade Federal de Lavras, protocolo $n^{\text {o }}$. 008/2015. Foram utilizados 88 suínos, machos castrados (cruzamento de fêmeas DanBred - DB90 x machos PIC - AGPIC337), com peso inicial de $81,6 \pm 5,22 \mathrm{~kg}$, alojados em galpão de terminação, com baias de piso concretado $(2,3 \times 1,5 \mathrm{~m})$, dotado de comedouros semiautomáticos e bebedouros do tipo chupeta. O período experimental total foi de 28 dias, durante a terminação, não sendo realizado um período de adaptação pré-experimental. A temperatura ambiente média variou de 19,6 a $33,4^{\circ} \mathrm{C}$, enquanto a umidade média oscilou entre 43,2 e $82,1 \%$ durante o experimento.

O delineamento experimental foi em blocos completos ao acaso (DBC), considerando-se o peso vivo como variável de blocagem, com quatro tratamentos e 11 repetições, sendo a parcela experimental representada por dois animais, totalizando 88 animais. Os suínos foram divididos em quatro grupos, que receberam os seguintes tratamentos: 1) controle: dieta basal sem suplementação adicional de minerais durante 28 dias; 2) CrFe: dieta basal + 400ppb de cromo e 100ppm de ferro durante 28 dias; 3 ) MgSe: dieta basal durante 28 dias $+300 p p m$ de 
magnésio e 3 ppm de selênio nos últimos sete dias antes do abate; 4) CrFeMgSe: dieta basal + $400 \mathrm{ppb}$ de cromo e $100 \mathrm{ppm}$ de ferro durante 28 dias $+300 \mathrm{ppm}$ de magnésio e $3 \mathrm{ppm}$ de selênio nos últimos sete dias antes do abate. Os minerais fornecidos foram todos de fonte orgânica (Biometal $^{\circledR}$, NPA - Núcleo de Pesquisas Aplicadas Ltda., Brasil), sendo eles: picolinato de cromo $(11,68 \%)$, ferro $(16,33 \%)$, bisglicinato de magnésio $(9,33 \%)$ e glicinato de selênio $(0,98 \%)$. O tempo de fornecimento dos minerais foi baseado em estudos encontrados na literatura.

As dietas experimentais (Tab. 1) foram formuladas para atender as exigências mínimas de suínos em terminação (Rostagno, 2011) e suplementadas de acordo com os tratamentos citados acima, sendo os minerais incluídos em substituição ao caulim. Foi fornecida dieta e água ad libitum diariamente e realizada a pesagem dos resíduos para a estimativa do consumo diário. Os animais foram pesados no início e final do experimento, para a determinação do ganho de peso diário e da conversão alimentar no período. Quando do término do período experimental, eles foram encaminhados para abatedouro frigorífico comercial, em caminhão apropriado. Após a chegada ao frigorífico, foram mantidos por 12 horas em pocilgas cobertas para descanso, onde receberam água por meio de bebedouros do tipo chupeta e permaneceram em jejum de alimentos sólidos.

Tabela 1. Composição da dieta basal fornecida aos suínos durante o período de terminação

\begin{tabular}{|c|c|}
\hline Ingredientes & Dieta basal (kg) \\
\hline Milho & 75,70 \\
\hline Farelo de soja & 20,00 \\
\hline Óleo de soja & 1,00 \\
\hline Fosfato bicálcico & 0,77 \\
\hline Calcário & 0,56 \\
\hline Sal & 0,35 \\
\hline Premix mineral $^{1}$ & 0,18 \\
\hline Premix vitamínico $^{2}$ & 0,30 \\
\hline L- lisina $50,7 \%$ & 0,47 \\
\hline DL- metionina $99 \%$ & 0,09 \\
\hline L- treonina $98 \%$ & 0,10 \\
\hline Ractopamina & 0,05 \\
\hline Caulim/Suplementação de minerais ${ }^{3}$ & 0,45 \\
\hline TOTAL & 100,00 \\
\hline \multicolumn{2}{|l|}{ Valores nutricionais estimados ${ }^{4}$} \\
\hline Proteína bruta $(\%)$ & 15,01 \\
\hline Energia metabolizável (kcal/kg) & 3240 \\
\hline Cálcio $(\%)$ & 0,47 \\
\hline Fósforo disponível (\%) & 0,23 \\
\hline Lisina digestível (\%) & 0,88 \\
\hline Metionina digestível (\%) & 0,31 \\
\hline Metionina + cistina $(\%)$ & 0,54 \\
\hline \multicolumn{2}{|c|}{ 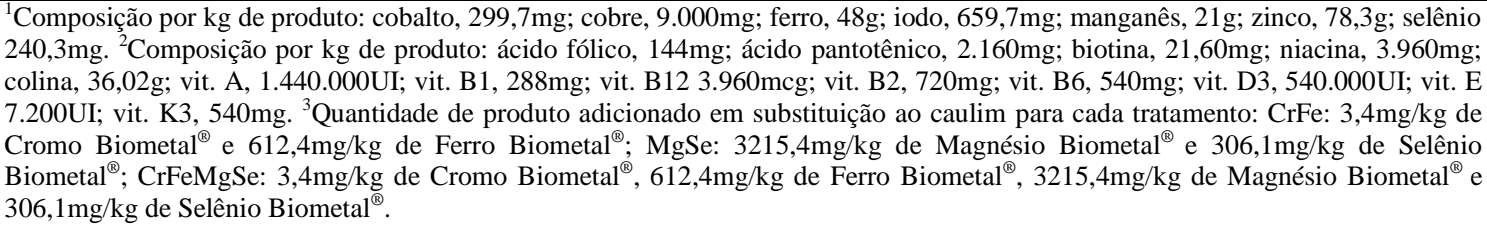 } \\
\hline
\end{tabular}

Quantidade de minerais por $\mathrm{kg}$ da dieta nos tratamentos: controle: $86,4 \mathrm{mg} / \mathrm{kg}$ de ferro e $0,43 \mathrm{mg} / \mathrm{kg}$ de selênio; $\mathrm{CrFe}: 0,4 \mathrm{mg} / \mathrm{kg}$ de cromo, $186,4 \mathrm{mg} / \mathrm{kg}$ de ferro e $0,43 \mathrm{mg} / \mathrm{kg}$ de selênio; MgSe: $86,4 \mathrm{mg} / \mathrm{kg}$ de ferro, $300 \mathrm{mg} / \mathrm{kg}$ de magnésio e $3,43 \mathrm{mg} / \mathrm{kg}$ de selênio; $\mathrm{CrFeMgSe}: 0,4 \mathrm{mg} / \mathrm{kg}$ de cromo, $186,4 \mathrm{mg} / \mathrm{kg}$ de ferro, $300 \mathrm{mg} / \mathrm{kg}$ de magnésio e $3,43 \mathrm{mg} / \mathrm{kg}$ de selênio.

Após o abate, as carcaças foram pesadas para obtenção do peso de carcaça quente (PCQ) sendo 
posteriormente destinadas à câmara fria, onde permaneceram por 24 horas. Após esse período, sob refrigeração, foram novamente pesadas para mensuração do peso de carcaça fria (PCF). Mensurou-se ainda o comprimento de carcaça (CC), em centímetros, com o auxílio de uma trena, e a espessura de toucinho (ET), a profundidade de lombo (PL), a área de olho-delombo (AOL) e a área de gordura em milímetros, usando-se um paquímetro digital (DIGIMESS, China). Todas essas variáveis foram avaliadas na altura da última costela no músculo Longissimus thoracis (LT), segundo Bridi e Silva (2009). O rendimento (RCM em \%) e a quantidade (QCM em $\mathrm{kg}$ ) de carne foram calculados de acordo com as equações: $\operatorname{RCM}(\%)=65,92-[(0,685 \mathrm{x}$ espessura de toucinho em $\mathrm{mm})+(0,094 \mathrm{x}$ profundidade de lombo em $\mathrm{mm})$ - $(0,026 \mathrm{x}$ peso de carcaça fria) $]$ e QCM $(\mathrm{kg})=7,38-[(0,48 \times$ espessura de toucinho em $\mathrm{mm})+(0,059 \mathrm{x}$ profundidade de lombo em $\mathrm{mm})+(0,525 \mathrm{x}$ peso de carcaça quente)], propostas por Guidoni (2001).

Visando analisar a viabilidade econômica da suplementação mineral, realizou-se uma cotação dos preços dos ingredientes da ração (referente a maio de 2016), para a estimativa do custo da dieta (por $\mathrm{kg}$ de ração balanceada), calculado pela soma dos preços multiplicados pela quantidade de cada ingrediente adicionado em cada quilograma de ração. Calculou-se também o custo diário da dieta, considerando-se o consumo e o custo individual da ração para cada período (21 e sete dias), sendo calculado, posteriormente, o custo alimentar médio diário do período todo (28 dias). Por fim, obteve-se o custo por kg de ganho de peso dos animais, por meio da relação entre o custo alimentar diário pelo ganho de peso médio diário, conforme metodologia de Lopes et al. (2012). Realizou-se, ainda, o cálculo de índice de bonificação - IB (IB = 23,6 + 0,286 $\times$ PCQ + Pcmf), em que Pcmf é a porcentagem de carne na carcaça resfriada, calculada segundo a fórmula: Pcmf = $100 \mathrm{x}$ (quantidade de carne fria $\div \mathrm{PCF})$, e calculou-se também a receita bruta $\mathrm{RB}(\mathrm{RB}=($ preço $) \times[(\mathrm{PCQ} \div \mathrm{RCM}(\%)) \times$ (bonificação), de acordo com Guidoni (2001). Os custos calculados foram convertidos do real para o dólar, considerando-se a cotação de R \$ 3,91, referente a agosto de 2018 .

$\mathrm{Na}$ análise estatística, todas as variáveis mensuradas foram testadas para normalidade pelo teste de Shapiro-Wilk, e aquelas que não apresentaram distribuição normal foram transformadas utilizando-se a opção NORMAL do PROC RANK do SAS (SAS 9.3 Intit. Inc., Cary, NC). Todos os dados foram submetidos à análise de variância (ANOVA), sendo aquelas variáveis que apresentaram diferenças significativas, a um nível de significância de 5\% de probabilidade, submetidas ao teste de médias de Tukey.

\section{RESULTADOS E DISCUSSÃO}

Os animais suplementados com CrFeMgSe apresentaram redução no peso final $(\mathrm{P}=0,003)$ e ganho de peso diário $(\mathrm{P}=0,002)$ em relação ao grupo controle. $\mathrm{O}$ uso de $\mathrm{CrFe}$ não diferiu do grupo com os quatro minerais, e o grupo $\mathrm{MgSe}$ apresentou ganho intermediário aos demais (Tab. 2). A suplementação com $\mathrm{CrFeMgSe}$ proporcionou redução de $10 \%$ no consumo da dieta durante todo o período experimental $(\mathrm{P}=0,027)$, comparado ao grupo controle. Esse comportamento ocorreu quando se adicionou magnésio e selênio à dieta, fato observado ao se analisar o consumo do dia 22 ao dia 28 do experimento, havendo queda de 27 e $32 \%$ no consumo $(\mathrm{P}=0,001)$ dos grupos $\mathrm{MgSe} \mathrm{e}$ $\mathrm{CrFeMgSe}$ em relação ao grupo controle. O grupo suplementado com a associação dos quatro minerais apresentou, ainda, menor eficiência alimentar $(\mathrm{P}=0,001)$ (Tab. 2).

O uso de cromo e ferro isoladamente não demonstra efeitos sobre as características de desempenho de suínos em terminação (Matthews et al., 2003; Apple et al., 2007). O magnésio fornecido durante cinco dias antes do abate também não revelou efeito no ganho de peso e na conversão alimentar dos animais (Hamilton et al., 2002), assim como o selênio não se mostrou eficiente em melhorar o desempenho de suínos (Mateo et al., 2007), resultados semelhantes aos obtidos no presente estudo, quando utilizados de forma associada. 
Efeito da suplementação...

Tabela 2. Médias de desempenho e características de carcaça de suínos em terminação, suplementados com diferentes associações entre minerais

\begin{tabular}{|c|c|c|c|c|c|c|c|}
\hline \multirow{2}{*}{ Variáveis } & \multicolumn{4}{|c|}{ Dietas } & \multirow{2}{*}{ CV (\%) } & \multirow{2}{*}{ EPM } & \multirow{2}{*}{ Valor $\mathrm{p}$} \\
\hline & Controle $^{1}$ & $\mathrm{CrFe}^{2}$ & $\mathrm{MgSe}^{3}$ & $\mathrm{CrFeMgSe}^{4}$ & & & \\
\hline PI (kg) & 78,86 & 78,93 & 79,05 & 78,88 & 6,66 & 1,64 & 0,578 \\
\hline PF (kg) & $114,82^{\mathrm{a}}$ & $113,55^{\mathrm{a}}$ & $110,46^{\mathrm{ab}}$ & $107,65^{\mathrm{b}}$ & 7,71 & 2,54 & 0,003 \\
\hline GPD (kg) & $1,28^{\mathrm{a}}$ & $1,24^{\mathrm{a}}$ & $1,12^{\mathrm{ab}}$ & $1,03^{\mathrm{b}}$ & 16,10 & 0,05 & 0,002 \\
\hline CDT (kg) & $3,21^{\mathrm{a}}$ & $3,10^{\mathrm{ab}}$ & $2,97^{\mathrm{ab}}$ & $2,89^{\mathrm{b}}$ & 12,55 & 0,11 & 0,027 \\
\hline CD1 (kg) & 3,28 & 3,13 & 3,23 & 3,17 & 11,75 & 0,12 & 0,525 \\
\hline CD2 (kg) & $3,01^{\mathrm{a}}$ & $3,01^{\mathrm{a}}$ & $2,19^{\mathrm{b}}$ & $2,06^{\mathrm{b}}$ & 26,30 & 0,16 & 0,001 \\
\hline $\mathrm{CA}(\mathrm{kg})$ & $2,51^{\mathrm{b}}$ & $2,51^{\mathrm{b}}$ & $2,67^{\mathrm{ab}}$ & $2,88^{\mathrm{a}}$ & 10,43 & 0,07 & 0,002 \\
\hline EA & $0,40^{\mathrm{a}}$ & $0,40^{\mathrm{a}}$ & $0,38^{\mathrm{ab}}$ & $0,35^{\mathrm{b}}$ & 9,41 & 0,01 & 0,001 \\
\hline PCQ (kg) & $90,88^{\mathrm{a}}$ & $90,11^{\mathrm{ab}}$ & $87,63^{\mathrm{ab}}$ & $86,72^{\mathrm{b}}$ & 8,42 & 2,05 & 0,008 \\
\hline $\mathrm{PCF}(\mathrm{kg})$ & $89,06^{\mathrm{a}}$ & $88,31^{\mathrm{ab}}$ & $85,88^{\mathrm{ab}}$ & $84,98^{\mathrm{b}}$ & 8,42 & 2,01 & 0,008 \\
\hline RCQ (\%) & 79,12 & 79,35 & 79,63 & 80,65 & 2,68 & 0,45 & 0,086 \\
\hline $\mathrm{CC}(\mathrm{cm})$ & 101,64 & 101,82 & 100,20 & 101,27 & 3,59 & 0,87 & 0,349 \\
\hline PL (mm) & $65,17^{\mathrm{a}}$ & $66,34^{\mathrm{a}}$ & $64,22^{\mathrm{ab}}$ & $60,66^{\mathrm{b}}$ & 9,07 & 1,18 & 0,007 \\
\hline ÁOL $\left(\mathrm{cm}^{2}\right)$ & $49,23^{\mathrm{ab}}$ & $50,34^{\mathrm{a}}$ & $47,41^{\mathrm{ab}}$ & $46,46^{\mathrm{b}}$ & 11,09 & 1,16 & 0,021 \\
\hline $\mathrm{AG}\left(\mathrm{cm}^{2}\right)$ & 17,09 & 16,06 & 15,54 & 20,43 & 55,45 & 2,04 & 0,293 \\
\hline $\mathrm{ET}(\mathrm{mm})$ & 15,41 & 13,69 & 14,04 & 14,69 & 24,45 & 0,78 & 0,367 \\
\hline $\mathrm{RCM}(\%)$ & 51,97 & 52,97 & 52,88 & 52,76 & 4,17 & 0,49 & 0,387 \\
\hline QCM (kg) & $51,43^{\mathrm{a}}$ & $51,94^{\mathrm{a}}$ & $50,34^{\mathrm{ab}}$ & $49,33^{\mathrm{b}}$ & 7,42 & 0,99 & 0,005 \\
\hline
\end{tabular}

${ }^{1}$ Controle: dieta basal; ${ }^{2} \mathrm{CrFe}$ : dieta basal $+400 \mathrm{ppb}$ de cromo e $100 \mathrm{ppm}$ de ferro; ${ }^{3} \mathrm{MgSe}$ : dieta basal $+300 \mathrm{ppm}$ de magnésio e $3 \mathrm{ppm}$ de selênio; ${ }^{4} \mathrm{CrFeMgSe}$ dieta basal $+400 \mathrm{ppb}$ de cromo, $100 \mathrm{ppm}$ de ferro, 300ppm de magnésio e 3ppm de selênio; PI: peso inicial; PF: peso final; GPD: ganho de peso diário; CDT: consumo diário total do dia 0 ao 28; CD1: consumo diário do dia 0 ao 21; CD2: consumo diário do dia 22 ao 28; CA: conversão alimentar; EA: eficiência alimentar; PQC: peso de carcaça quente; PCF: peso de carcaça fria; RCQ: rendimento de carcaça quente; CC: comprimento de carcaça; PL: profundidade de lombo; AOL: área de olho-de-lombo; AG: área de gordura; ET: espessura de toucinho; RCM: rendimento de carne magra; QCM: quantidade de carne magra. ${ }^{\text {ab }}$ Médias seguidas de mesma letra nas linhas não diferem estatisticamente ao nível de significância de $5 \%$ de probabilidade pelo teste de Tukey.

Para o tratamento com CrFeMgSe, houve redução de aproximadamente $5 \%$ no peso de carcaça quente (PCQ) $(\mathrm{P}=0,008)$ e fria $(\mathrm{PCF})$ $(\mathrm{P}=0,008)$ em relação ao grupo controle; já os grupos $\mathrm{CrFe}$ e $\mathrm{MgSe}$ apresentaram resultados semelhantes aos demais (Tab. 2). Houve também redução de $7 \%$ na profundidade de lombo (PL) $(\mathrm{P}=0,007), 6 \%$ na área de olho-de-lombo (AOL) $(\mathrm{P}=0,021)$ e $4 \%$ na quantidade de carne (QCM $\mathrm{kg})(\mathrm{P}=0,005)$ para $\mathrm{CrFeMgSe}$ comparado ao grupo controle. Observou-se aumento de 2,3\% na $\mathrm{AOL}(\mathrm{P}=0,021)$ para o grupo $\mathrm{CrFe}$ em relação ao controle, apesar de não ter havido diferença estatística entre eles. Tal resultado, que está de acordo com estudos reportando o uso de cromo (Xi et al., 2001), possivelmente se deveu ao fato de esse mineral potencializar a captação de glicose pela célula (Evans e Bowman, 1992) e atuar na incorporação e utilização de aminoácidos, síntese proteica e RNA (Okada et al., 1983). Estudos têm demonstrado que esse mineral é constituinte de um oligopeptídeo chamado cromodulina, que tem por função manter a conformação ativa dos receptores de insulina por meio da ativação da proteína tirosina quinase (Vincent, 2000), amplificando os sinais da insulina nas células, com consequente estímulo da translocação de GLUT4, o que aumenta a captação de glicose e aminoácidos e, portanto, favorece a síntese proteica (Kreider, 1999).

Os parâmetros de rendimento e comprimento de carcaça, área de gordura, espessura de toucinho e rendimento de carne magra não foram influenciados pelo uso da suplementação mineral nas dietas $(\mathrm{P}>0,05)$ (Tab. 2). A utilização de cromo, ferro, magnésio e selênio, de forma isolada na dieta, não tem revelado efeito sobre a quantidade de carne magra, o PCQ e a AOL (Mahan et al., 1999; O'Sullivan et al., 2002; Machado et al., 2008; Peres et al., 2014). No presente estudo, todavia, a associação de $\mathrm{CrFeMgSe}$ influenciou de forma negativa esses 
parâmetros, e a redução observada nos valores de PCQ, PCF, AOL e na quantidade de carne magra para esse grupo foi relacionada ao menor peso de abate.

No presente estudo, a suplementação com selênio foi realizada por meio de fonte orgânica, durante sete dias antes do abate e com uma dosagem de 3ppm. Contudo, pôde-se observar (Tab. 2) que o consumo da dieta dos grupos tratados com esse mineral apresentou uma redução, o que pode ter sido causado pela dosagem mais elevada. Há relatos na literatura de queda linear do consumo e ganho de peso de suínos suplementados com altas doses de selênio (4 a 20ppm), sendo esse efeito mais pronunciado quando do uso de fonte inorgânica (Goehring et al., 1983; Goehring et al., 1984; Kim e Mahan, 2001). Banholzer e Heinritzi (1998) relataram a anorexia como um dos sinais típicos de toxicidade aguda por selênio e a redução no consumo nos casos de toxicidade crônica pelo mineral.
$\mathrm{Na}$ literatura, não foram encontrados relatos da interferência desses quatro minerais entre si, na dieta de suínos. A possível interação entre eles e a dose mais elevada de selênio podem ter sido a causa da redução no consumo com consequente diminuição no peso de abate e nos parâmetros de carcaça, havendo, então, a necessidade de maiores esclarecimentos em relação à sua utilização em conjunto.

O custo das dietas $\mathrm{CrFe}, \mathrm{MgSe}$ e $\mathrm{CrFeMgSe}$ apresentou, respectivamente, aumento de 23\%, $26 \%$ e $31 \%$ em relação à dieta basal (Tab. 3). Houve uma redução no custo diário da dieta do dia 21 ao $28(\mathrm{P}=0,001)$ das dietas $\mathrm{MgSe}$ e $\mathrm{CrFeMgSe}$ comparado ao custo da dieta do grupo controle, devido à redução no consumo $(\mathrm{P}=0,001)$ observada para esses grupos nos últimos sete dias do experimento. Ainda, $\mathrm{CrFeMgSe}$ apresentou aumento de $20 \%$ no custo da dieta por quilograma de ganho de peso $(\mathrm{P}=0,003)$, em relação ao grupo controle, devido ao fato de os animais desse grupo terem apresentado, além de maior custo da dieta, piores índices de conversão e eficiência alimentar.

Tabela 3. Custo da dieta total, por dia e por kg de ganho de peso de suínos em terminação, suplementados com diferentes associações de minerais

\begin{tabular}{|c|c|c|c|c|c|c|c|}
\hline \multirow{2}{*}{ Variáveis } & \multicolumn{4}{|c|}{ Dietas } & \multirow{2}{*}{$\begin{array}{l}\text { CV } \\
(\%)\end{array}$} & \multirow{2}{*}{ EPM } & \multirow{2}{*}{ Valor $\mathrm{p}$} \\
\hline & Controle $^{1}$ & $\mathrm{CrFe}^{2}$ & $\mathrm{MgSe}^{3}$ & $\mathrm{CrFeMgSe}^{4}$ & & & \\
\hline $\mathrm{CtD}(\mathrm{R} \$ / \mathrm{kg})$ & 0,27 & 0,33 & 0,34 & 0,36 & - & - & - \\
\hline CtDd1 $(\mathrm{R} \$)$ & 0,89 & 0,85 & 0,83 & 0,87 & 13,98 & 0,036 & 0,570 \\
\hline $\mathrm{CtDd} 2(\mathrm{R} \$)$ & $0,81^{\mathrm{a}}$ & $0,82^{\mathrm{a}}$ & $0,55^{\mathrm{b}}$ & $0,55^{\mathrm{b}}$ & 27,15 & 0,041 & 0,001 \\
\hline CtDTd $(\mathrm{R} \$)$ & 0,87 & 0,84 & 0,76 & 0.79 & 14,43 & 0,033 & 0,061 \\
\hline CtDGP $(\mathrm{R} \$)$ & $0,69^{b}$ & $0.69^{b}$ & $0,70^{\mathrm{ab}}$ & $0,83^{\mathrm{a}}$ & 16,98 & 0,036 & 0,003 \\
\hline $\mathrm{IB}^{5}$ & $27,47^{\mathrm{ab}}$ & $27,69^{a}$ & $27,44^{\mathrm{ab}}$ & $27,23^{\mathrm{b}}$ & 1,86 & 0,11 & 0,034 \\
\hline $\mathrm{RB}(\mathrm{R} \$)^{6}$ & $206,75^{\mathrm{a}}$ & $206,15^{\mathrm{a}}$ & $197,94^{\mathrm{ab}}$ & $192,13^{\mathrm{b}}$ & 5,90 & 2,53 & 0,001 \\
\hline
\end{tabular}

${ }^{1}$ Controle: dieta basal; ${ }^{2} \mathrm{CrFe}$ : dieta basal $+400 \mathrm{ppb}$ de cromo e $100 \mathrm{ppm}$ de ferro; ${ }^{3} \mathrm{MgSe}:$ dieta basal $+300 \mathrm{ppm}$ de magnésio e 3ppm de selênio; ${ }^{4} \mathrm{CrFeMgSe}$ dieta basal $+400 \mathrm{ppb}$ de cromo, $100 \mathrm{ppm}$ de ferro, 300ppm de magnésio e $3 \mathrm{ppm}$ de selênio; ${ }^{5} \mathrm{IB}=23,6+0,286 \times \mathrm{PCQ}+\mathrm{Pcmf}$ (porcentagem de carne na carcaça fria); ${ }^{6} \mathrm{RCT}=($ Preço $)[(\mathrm{Pcarq} \div$ Rendcarq)*(Bonificação); CV: coeficiente de variação; EPM: erro-padrão da média; CtD: custo da dieta; CtDd1: custo da dieta por dia, do dia 0 a 21; CtDd2: custo da dieta por dia, do dia 22 a 28; CtDTd: custo da dieta diário do dia 0 ao 28; CtDGP: custo da dieta por kg de ganho de peso; IB: índice de bonificação; RB: receita bruta. ${ }^{\text {ab }}$ Médias seguidas de mesma letra nas linhas não diferem estatisticamente ao nível de significância de 5\% de probabilidade pelo teste de Tukey.

O índice de bonificação é uma estratégia de pagamento adicional por qualidade, utilizada como meio de incentivo à produção de carcaças com maior quantidade de carne e menos gordura e faz parte do cálculo da receita, que nada mais é do que o valor pago ao produtor pela carcaça após o abate (Guidoni, 2001). Esse índice foi maior para $\mathrm{CrFe}$, indicando carcaças de melhor qualidade, o que impacta diretamente o seu preço de venda, observado pelo maior valor de receita para essas. Em contrapartida, foi menor para $\mathrm{CrFeMgSe} \quad(\mathrm{P}=0,034)$, resultando em menor preço de venda em relação aos demais. Os grupos controle e MgSe apresentaram médias intermediárias aos demais. O cálculo da receita considera os valores de PCQ e RC e, apesar de o rendimento não ter sido influenciado pelas dietas, o menor peso de carcaça apresentado pelo 
grupo $\mathrm{CrFeMgSe}$ em relação ao grupo controle impactou negativamente $(7,1 \%)$ o preço pago ao produtor pela carcaça $(\mathrm{P}=0,001)$ (Tab. 3).

Como as características de desempenho e carcaça dos animais que receberam cromo mais ferro e magnésio mais selênio, associados dois a dois, não foram negativamente afetadas em relação ao grupo controle, o seu uso demonstra ser uma alternativa economicamente viável na terminação de suínos, pela possibilidade de melhorias na qualidade da carne e, também, pela diminuição da incidência de carnes PSE (D'Souza et al., 2000; Apple et al., 2007; Tarsitano et al., 2013; Peres et al., 2014; Calvo et al., 2016). Em contrapartida, o uso associado dos quatro minerais, além de reduzir o desempenho e os parâmetros de carcaça, aumentou o custo da dieta e diminuiu a receita. Visto que 70 a $80 \%$ do custo total de produção de suínos correspondem à alimentação (ABCS, 2014), a viabilidade para o seu uso somente estaria condicionada a um pagamento diferenciado por esse produto, principalmente em relação a possíveis benefícios para a qualidade da carne.

\section{CONCLUSÕES}

O uso de cromo mais ferro e magnésio mais selênio, associados dois a dois, não altera os parâmetros de desempenho e características de carcaça, podendo ser uma alternativa na busca de melhor qualidade de carne. Contudo, a associação dos quatro minerais promove piora no desempenho, resultando em carcaças mais leves e com menor quantidade de carne, com consequente aumento no custo da dieta. Entretanto, mais estudos são necessários relacionados à utilização associada desses minerais, em busca de maiores esclarecimentos a respeito da sua ação conjunta.

\section{REFERÊNCIAS}

APPLE, J.K.; WALLIS-PHELPS, W.A.; MAXWELL, C.V. et al. Effect of supplemental iron on finishing swine performance, carcass characteristics, and pork quality during retail display. J. Anim. Sci., v.85, p.737-745, 2007.

BANHOLZER, E.; HEINRITZI, K. Selenium toxicosis in fattening pigs. J. Anim. Physiol. Anim. Nutr., v.8, p.158-162, 1998.
BRIDI, A.M.; SILVA, C.A. Avaliação da carne suína. Londrina: Midiograf, 2009. 97p.

CALVO, L.; TOLDRÁ, F.; ARISTOY, M.C. et al. Effect of dietary organic selenium on muscle proteolytic activity and water-holding capacity in pork. Meat Sci., v.121, p.1-11, 2016.

CLOSE, W.H. Organic minerals for pigs: an update. In: $15^{\text {th }}$ ALLTECH'S ANNUAL SYMPOSIUM OF BIOTECHNOLOGY IN THE FEED INDUSTRY, 1999, Loughborough, UK. Proceedings... Nottingham University Press, 1999, p.51-60.

D'SOUZA, D.N.; WARNER, R.D.; LEURY, B.J. et al. The effect of dietary magnesium aspartate supplementation on pork quality. $J$. Anim. Sci., v.76, p.104-109, 1998.

D'SOUZA, D.N.; WARNER, R.D.; LEURY, B.J. et al. The influence of dietary magnesium supplement type, and suplementation dose and duration, on pork quality and the incidence of PSE pork. Aust. J. Agric. Res., v.51, p.185-189, 2000.

EVANS, G.W.; BOWMAN, T.D. Chromium picolinate increases membrane fluidity and rate of insulin internalization. J. Inorg. Biochem., v.46, p.243-250, 1992.

GOEHRING, T.B.; OLSON, O.E.; PALMER, I.S.; LIBAL, G.W. Selenium toxicity in growing swine. S. Dakota Swine Field Day Proc. Res. Rep., v.6, p.17-20, 1983.

GOEHRING, T.B.; PALMER, I.S.; OLSON, O.E. et al. Toxic effects of selenium on growing swine fed corn-soybean meal diets. J. Anim. Sci., v.59, p.733-737, 1984.

GUIDONI, A.L. Melhoria de processos para a tipificação e valorização de carcaças suínas no Brasil. In: CONFERÊNCIA INTERNACIONAL VIRTUAL SOBRE QUALIDADE DE CARNE SUÍNA, 2000, Concórdia, SC. Anais... Concórdia: Embrapa Suínos e Aves, 2001. p.221-234. (Resumo).

HAMILTON, D.N.; ELLIS, M.; HEMANN, M.D. et al. The impact of longissimus glycolytic potential and short-term feeding of magnesium sulfate heptahydrate prior to slaughter on carcass characteristics and pork quality. J. Anim. Sci., v.80, p.1586-1592, 2002. 
JANG, Y.D.; CHOI, H.B.; DUROSOY, S. et al. Comparison of bioavailability of organic selenium sources in finishing pigs. AsianAustralas. J. Anim. Sci., v.23, p.931-936, 2010.

KIM, Y.Y.; MAHAN, D.C. Comparative effects of high dietary levels of organic and inorganic selenium on selenium toxicity of growingfinishing pigs. J. Anim. Sci., v.79, p.942-948, 2001.

KREIDER, R.B. Dietary supplements and the promotion of muscle growth with resistance exercise. Sport Med., v.27, p.97-110, 1999.

LOPES, M.A.; LAGE, L.A.; LOPES, F.C.F. et al. Economic viability of feeding dairy cows on diets containing different levels of soybean oil. Rev. Bras. Zootec., v.41, p.2085-2091, 2012.

MACHADO, O.D.; FONTES, D.O.; FERREIRA, J.M. et al. Desempenho e qualidade da carne de suínos suplementados com magnésio e creatina no período pré-abate. Braz. J. Food Technol., v.11, p.211-220, 2008.

MAHAN, D.C.; CLINE, T.R.; RICHERT, B. Effects of dietary levels of selenium-enriched yeast and sodium selenite as selenium sources fed to growing-finishing pigs on performance, tissue selenium, serum glutathione peroxidase activity, carcass characteristics, and loin quality. J. Anim. Sci., v.77, p.2172-2179, 1999.

MATEO, R.D.; SPALLHOLZ, J.E.; ELDER, R. et al. Efficacy of dietary selenium sources on growth and carcass characteristics of growingfinishing pigs fed diets containing high endogenous selenium. J. Anim. Sci., v.85, p.1177-1183, 2007.

MATTHEWS, J.O.; HIGBIE, A.D.; SOUTHERN, L.L. et al. Effect of chromium propionate and metabolizable energy on growth, carcass traits, and pork quality of growingfinishing pigs. J. Anim. Sci., v.81, p.191-196, 2003.

MCDOWELL, L.R. Iron. In: MCDOWELL, L.R. Minerals in animal and human nutrition. 2ed. Amsterdam: Elsevier, 2003. p.203-232.
O'SULliVAN, M.; BYRNE, D.; STAGSTED, J. et al. Sensory colour assessment of fresh meat from pigs supplemented with iron and vitamin E. Meat Sci., v.60, p.253-265, 2002.

OKADA, S.; SUZUKI, M.; OHBA, H. Enhancement of ribonucleic acid synthesis by chromium (III) in mouse liver. J. Inorg. Biochem., v.19, p.95-103, 1983.

PERES, L.M.; BRIDI, A.M.; SILVA, C.A. et al. Effect of supplementing finishing pigs with different sources of chromium on performance and meat quality. Rev. Bras. Zootec., v.43, p.369-375, 2014.

PRODUÇÃO de suínos: teoria e prática. Brasília: ABCS, 2014. 908p.

ROSTAGNO, H.S. Tabelas brasileiras para aves e suínos: composição de alimentos $e$ exigências nutricionais. 3.ed. Viçosa, MG: Univerisdade Federal de Viçosa, 2011. 252p.

SURAI, P. Organic selenium: benefits to animals and humans, a biochemist's view. In: $16^{\text {th }}$ ALLTECH'S ANNUAL SYMPOSIUM OF BIOTECHNOLOGY IN THE FEED INDUSTRY, 2000, Nottingham, UK. Proceedings... Nottingham University Press, 2000. p.205-260.

TARSITANO, M.A.; BRIDI, A.M.; SILVA, C.A. et al. Magnesium supplementation in swine finishing stage: performance, carcass characteristics and meat quality. Semin. Ciênc. Agrár., v.34, p.3105-3118, 2013.

VINCENT, J.B. The Biochemistry of chromium. J. Nutr., v.130, p.715-718, 2000.

XI, G.; XU, Z.; WU, S. et al. Effect of chromium picolinate on growth performance, carcass characteristics, serum metabolites and metabolism of lipid in pigs. Asian-Australas. J. Anim. Sci., v.14, p.258-262, 2001.

YU, B.; HUANG, W.J.; CHIOU, P.W.S. Bioavailability of iron from amino acid complex in weanling pigs. Anim. Feed Sci. Technol., v.86, p.39-52, 2000. 